\title{
Knowledge, attitude and practice of
} health care providers toward prescribing factor replacement at federally funded haemophilia treatment centres in the United States

M. Bloomberg, K. Sargenton, K. Gattamorta, D. Anglade

Factor replacement is currently the standard of care to prevent or treat bleeding episodes in haemophilia patients. This study examined current prescribing practices of factor therapy for patients at haemophilia treatment centres (HTCs) in the United States. Aims: The aims were to evaluate the driving forces for prescribing factor products, to evaluate current attitudes and knowledge toward factor product and industry, and to discuss the implications for health care providers in practice. Methods: An anonymous electronic survey was distributed to $744 \mathrm{HTC}$ health care providers (HCPs); 118 responses were analysed. Results: The most common driving force

MAYA BLOOMBERG

University of Miami Haemophilia Treatment Center,

Miami, FL, US.

KRYSTEN SARGENTON

University of Miami Haemophilia Treatment Center,

Miami, FL, US

KARINA GATTAMORTA

University of Miami School of Nursing \& Health Studies, Miami, FL, US

DEBBIE ANGLADE

University of Miami School of Nursing \& Health Studies,

Miami, FL, US

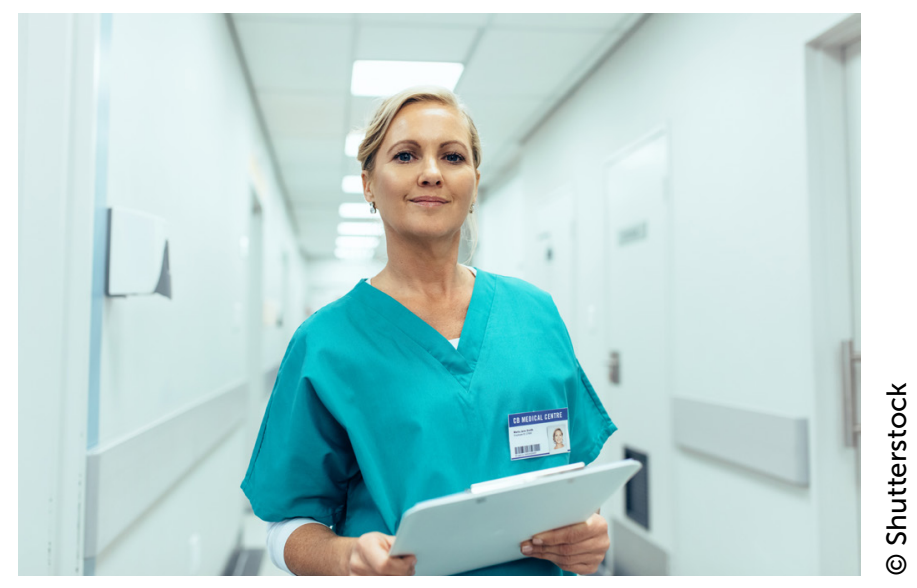

As the choice of treatment options increases, a survey on prescribing practices in the US looks at the driving forces that lead health care professionals to change a patient's factor concentrate, and their perceptions of what motivates patients to request a change to their prescription.

for HCPs to change a patient's factor product was poor response to current therapy, while the most common perception of patients' motivation to switch products was the potential for fewer infusions. HCPs with strong influence over the prescribed therapy identified inadequate pharmacokinetic (PK) studies as an important driving force; patients/caregivers perceived as having a strong influence over which

This is an Open Access article distributed under the terms of the Creative Commons Attribution-NonCommercial-NoDerivs License (https://creativecommons.org/licenses/by-nc-nd/3.0/) which permits use and distribution in any medium, provided the original work is properly cited, the use is non-commercial, and no modifications or adaptations are made. Copyright is retained by the authors. 
therapy is prescribed selected less frequent dosing as an important motivator. HCPs who allow patients/ caregivers to have a strong influence over which factor is prescribed were more likely to cite patient/caregiver request as a significant driving force for change in therapy. Conclusion: The haemophilia treatment landscape continues to evolve and is becoming increasingly complex. The multitude of treatment options available now offer choices, presenting a need to focus on patient-centric prophylaxis.

Keywords: haemophilia, factor replacement, prescribing patterns, attitude of health personnel, medical practice, professional knowledge

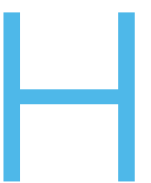

aemophilia is a hereditary bleeding disorder caused by a deficiency or absence of a protein that is essential for the formation of clots $^{[1]}$. Haemophilia A (deficiency in Factor VIII) and Haemophilia B (deficiency in Factor IX) are the most common serious coagulation factor deficiencies and primarily affect the male population in all ethnic groups ${ }^{[2]}$. Those affected are at risk for potentially life and/or limb-threatening bleeding with little or no trauma

While novel therapies continue to be researched and approved as treatment options for haemophilia, the World Federation of Hemophilia (WFH) recognises the replacement of missing clotting protein, known as anti-haemophilic factor product, as the standard of care to prevent and treat bleeding episodes ${ }^{[3]}$. Treatment consists of infusions of anti-haemophilic factor concentrates, either given 'as needed' to treat active bleeding episodes, (on-demand therapy), or given as regularly scheduled infusions (prophylaxis) ${ }^{[1]}$. Treating and patient communities are now on the cusp of a paradigm shift as a result of advances in both novel therapies and gene therapy options. This new era of multiple treatment options, including extended half-life products, subcutaneous injections and gene therapy, has created therapeutic challenges affecting the haemophilia population ${ }^{[4]}$

At this time, health care providers (HCPs) in the United States (US) exercise their best judgement in advising patients about their therapy options in terms of prevention and treatment of bleeding episodes ${ }^{[1]}$. HCPs, such as physicians and nurse practitioners, present the different options available for factor replacement to their patients and/or caregivers, discussing similarities and differences among products, efficacy and safety information. There are currently no evidence-based 'best' treatment options. After providing information and exploring the patient's preferences and goals with regard to their treatment, patients and caregivers together can make an individualised, educated decision on their specific factor therapy.

A thorough literature review did not identify any studies that evaluated current factor replacement prescribing practices among HCPs at haemophilia treatment centres (HTCs). In this study, HTC HCPs were electronically surveyed to gain a better understanding of their practices prescribing factor replacement. The survey omitted novel therapies as approval for use in non-inhibitor patients occurred during the conceptualisation of the study. The study's goals were to evaluate the driving forces behind the prescribing of factor concentrates in the US and to enhance the education of the haemophilia patient population about treatment options.

\section{METHODS}

This study was approved by the University of Miami Institutional Review Board (IRB).

\section{Sample population}

Study participants were exclusively health care providers currently working at federally funded HTCs in the US. This included haematologists, nurse practitioners (NPs), physician assistants (PAs), nurse coordinators, and staff nurses.

\section{Measurement instrument}

Data was collected in 2019 using a one-time electronic, anonymous survey created through the University of Miami's Qualtrics secure web-based survey application. Potential participants received an e-mail invitation with a unique embedded link for self-administering the survey.

The survey was a non-validated tool developed by the authors and comprised ten (10) demographic questions, five (5) questions specific to current prescribing practices, and five (5) questions on attitudes toward industry. The estimated survey completion time was 15-20 minutes.

An email distribution list was created using the Center for Disease Control and Prevention's (CDC) HTC directory, which was validated by HTC regional coordinators and the Partners in Bleeding Disorders Education organisation ${ }^{[5,6]}$. Survey invitations were distributed to 775 potential participants. Thirty-one (31) surveys were omitted as a result of incorrect emails, or providers responding that they either no longer worked at an HTC, or solely specialised in thrombosis. 
The survey response data was downloaded directly from the Qualtrics survey software into the Statistical Package for the Social Sciences (IBM SPSS, Armonk, New York), Version 25, for data computation and analysis. Analysis included simple descriptive analysis of demographic information and descriptive/frequency statistics to assess for missing data. To examine the driving forces for changing a patient's factor concentrate, mean $(M)$ responses for each driving force

Table 1. Participant demographic information

\begin{tabular}{|c|c|c|}
\hline & $\begin{array}{l}\text { NO. } \\
(\mathrm{N}=118)\end{array}$ & $\%$ \\
\hline $\begin{array}{l}\text { Gender } \\
\text { Female } \\
\text { Male } \\
\text { Missing data }\end{array}$ & $\begin{array}{l}70 \\
26 \\
22\end{array}$ & $\begin{array}{l}59.3 \% \\
22.0 \% \\
18.7 \%\end{array}$ \\
\hline $\begin{array}{l}\text { Current Position } \\
\text { Hematologist } \\
\text { Staff nurse } \\
\text { Advanced practice registered } \\
\text { nurse (NP) } \\
\text { Physician assistant } \\
\text { Nurse coordinator } \\
\text { Missing data }\end{array}$ & $\begin{array}{l}43 \\
4 \\
19 \\
1 \\
30 \\
21\end{array}$ & $\begin{array}{l}36.6 \% \\
3.4 \% \\
16.1 \% \\
\\
0.8 \% \\
25.4 \% \\
17.8 \%\end{array}$ \\
\hline $\begin{array}{l}\text { Nursing Education* } \\
\text { ADN } \\
\text { BSN } \\
\text { MSN } \\
\text { Doctorate (PhD, DNP, EdD) } \\
\text { Other }\end{array}$ & $\begin{array}{l}2 \\
22 \\
21 \\
4 \\
4\end{array}$ & $\begin{array}{l}3.8 \% \\
41.5 \% \\
39.6 \% \\
7.5 \% \\
7.5 \%\end{array}$ \\
\hline $\begin{array}{l}\text { Patient Population } \\
\text { Paediatric } \\
\text { Adults } \\
\text { Both } \\
\text { Missing data }\end{array}$ & $\begin{array}{l}43 \\
19 \\
34 \\
22\end{array}$ & $\begin{array}{l}36.4 \% \\
16.1 \% \\
28.8 \% \\
18.6 \%\end{array}$ \\
\hline $\begin{array}{l}\text { Federal Region of HTC } \\
\text { New England } \\
\text { Mid-Atlantic } \\
\text { Southeast } \\
\text { Great Lakes } \\
\text { Northern States } \\
\text { Great Plains } \\
\text { Mountain States } \\
\text { Western States }\end{array}$ & $\begin{array}{l}11 \\
11 \\
18 \\
20 \\
2 \\
17 \\
8 \\
10\end{array}$ & $\begin{array}{l}9.3 \% \\
9.3 \% \\
15.3 \% \\
16.9 \% \\
1.7 \% \\
14.4 \% \\
6.8 \% \\
8.5 \%\end{array}$ \\
\hline $\begin{array}{l}\text { HTC associated with } \\
\text { Academic centre } \\
\text { Private clinic or hospital } \\
\text { Community/public clinic or hospital } \\
\text { Independent, self-standing HTC } \\
\text { Missing data }\end{array}$ & $\begin{array}{l}70 \\
15 \\
11 \\
10 \\
12\end{array}$ & $\begin{array}{l}59.3 \% \\
12.7 \% \\
9.3 \% \\
8.5 \% \\
10.2 \%\end{array}$ \\
\hline
\end{tabular}

* $\mathrm{N}=53$ reflecting nurse only response were calculated, and the factors were ranked by level of importance, with one (1) being not important and five (5) being very important. The level of importance of HCPs' perceptions of patient motivation leading to a request for a change in prescribed factor concentrate was also analysed by calculating mean responses and ranking by level of importance. To determine whether provider level of importance or patient level of importance differed based on provider characteristics and industry practices, a series of Chi-Square analyses were conducted. When assumptions of Chi-Square were violated, Fisher's Exact Test was used instead.

\section{RESULTS}

A total of 118 surveys were completed, yielding a 15.9\% response rate. Missing data consisted of incomplete demographic information; however, these responses were included in the analysis as questions specific to prescribing practices and attitudes toward industry were complete.

\section{Demographics}

A summary of study participant demographic characteristics can be found in Table 1 . The highest response rates were from the Great Lakes (16.9\%), Southeast (15.3\%) and Great Plains (14.4\%) regions. The majority of respondents reported working at an HTC associated with an academic centre (59.3\%), with haematologists accounting for $36.6 \%$ of responses, followed by nurse coordinators (25.4\%) and NPs (16.1\%). Survey participants had an average age of 50.9 years (SD = 12.0, range 28-77). When further broken down by category, the average age of haematologists was 51.4 years ( $S D=10.7$, range $34-72)$, NPs 43.9 years $(S D=10.9$, range $28-65)$, PAs 35.0 years $(n=1)$, nurse coordinators 52.4 years (SD $=12.7$, range $28-77$ ), and staff nurses 53.0 years (SD $=17.3$, range $33-63$ ). The mean number of years working as a HCP was 23.68 years $(S D=11.67$, range $5-45)$ and mean length of time working in a HTC was 12.0 years (SD $=10.59$, range $1-40$ ), with $2.5 \%$ of providers having worked at a HTC for less than one year. Thirty-six percent (36.4\%) of HCPs reported being responsible for paediatric patients; $16.1 \%$ cared for adults only, and $28.8 \%$ cared for both children and adults. Seventy-one per cent (71.2\%) of respondents reported having a 340B Drug Pricing Program at their HTC ${ }^{[7]}$.

\section{Provider practices}

Provider responses to the level of importance assigned to various driving forces for changing a patient's 
Table 2. Driving forces for changing a patient's factor concentrate

\begin{tabular}{|c|c|c|c|c|c|}
\hline REASON & $\begin{array}{l}\text { NOT } \\
\text { IMPORTANT } \\
\text { N (\%) }\end{array}$ & $\begin{array}{l}\text { SOMEWHAT } \\
\text { IMPORTANT } \\
\text { N (\%) }\end{array}$ & $\begin{array}{l}\text { NEUTRAL } \\
\text { N (\%) }\end{array}$ & $\begin{array}{l}\text { IMPORTANT } \\
\text { N (\%) }\end{array}$ & $\begin{array}{l}\text { VERY } \\
\text { IMPORTANT } \\
\text { N (\%) }\end{array}$ \\
\hline Less frequent dosing option & $0(0)$ & $6(7.1)$ & $4(4.8)$ & $41(48.8)$ & $33(39.3)$ \\
\hline Lower out-of-pocked cost & $5(5.9)$ & $8(9.4)$ & $14(16.5)$ & $34(40.0)$ & $24(28.2)$ \\
\hline Insurance preferred drug list & $10(11.9)$ & $11(13.1)$ & $19(22.6)$ & $30(35.7)$ & $14(16.7)$ \\
\hline $\begin{array}{l}\text { Concerns about inhibitor } \\
\text { development }\end{array}$ & $3(3.5)$ & $6(10.6)$ & $11(23.5)$ & $27(55.3)$ & $38(44.7)$ \\
\hline $\begin{array}{l}\text { Strong commitment of manufacturer } \\
\text { to haemophilia community }\end{array}$ & $34(40.5)$ & $14(57.1)$ & $26(88.1)$ & $6(7.1)$ & $4(4.8)$ \\
\hline Patient/caregiver brand loyalty & 15 (17.9) & 15 (17.9) & $29(34.5)$ & $18(21.4)$ & $7(8.3)$ \\
\hline $\begin{array}{l}\text { Patient/caregiver requested a switch } \\
\text { in product }\end{array}$ & $0(0)$ & $5(6.0)$ & $8(9.6)$ & $38(45.8)$ & $32(38.6)$ \\
\hline $\begin{array}{l}\text { Therapy recommended by friend/ } \\
\text { family/acquaintance }\end{array}$ & $30(35.7)$ & $18(21.4)$ & $25(29.8)$ & $11(13.1)$ & $0(0)$ \\
\hline $\begin{array}{l}\text { Poor response to current therapy } \\
\text { (breakthrough bleeds) }\end{array}$ & $0(0)$ & $0(0)$ & $1(1.2)$ & $12(14.1)$ & $72(84.7)$ \\
\hline Inadequate PK studies & $0(0)$ & $4(4.8)$ & $12(14.3)$ & $27(32.1)$ & $41(48.8)$ \\
\hline Non-adherent to current therapy & $1(1.2)$ & $0(0)$ & $4(47.1)$ & $40(47.1)$ & 40 (47.1) \\
\hline Other & $1(12.5)$ & $0(0)$ & $0(0)$ & $2(25.0)$ & $5(62.5)$ \\
\hline
\end{tabular}

factor concentrate is summarised in Table 2. The most common driving forces for changing a patient's factor concentrate included: poor response to current therapy (breakthrough bleeds) $(M=4.84)$; non-adherence to current therapy ( $M=4.39)$; inadequate pharmacokinetic (PK) studies; 'Other' $(M=4.25)$; and less frequent dosing option $(M=4.20)$.

Table 3 summarises provider perceptions of patient motivations leading to a request to change their prescribed factor concentrate. These included less frequent dosing option $(M=4.55)$; poor response to current therapy $(M=4.36)$; factor characteristics (volume to be infused, mixing device, vial size) $(M=$ 4.14); lower out-of-pocket costs $(M=3.98)$; and patient/caregiver brand loyalty $(M=3.82)$.

Models also examined whether particular demographic factors predicted the likelihood of identifying a driving force as being 'important' or 'very important', both from the perspective of the provider and the patient. These indicated that age (above or below median age), experience (above or below median experience) and position (haematologist compared to NP/PA) were not significantly associated with a higher likelihood of endorsing any particular reason as important or very important.

When evaluating who typically initiates the conversation regarding switching a patient's factor therapy, the HCP (haematologist, NP, PA, nurse coordinator) was most common (56.0\%) followed by the patient/caregiver (23.8\%). An 'Other' option was included for this question, and several respondents reported a combination of both patient and provider initiating the conversations.

Haematologists (55.3\%) were primarily responsible for informing patients about factor therapy options, followed by NPs/PAs (23.5\%) and nurse coordinators (15.3\%). The majority of HTC providers reported patients/caregivers having a strong influence $(65.5 \%)$ or some influence $(33.3 \%)$ over which factor therapy is prescribed. When asked how much influence providers have over which factor therapy is prescribed, $58.8 \%$ reported having a strong influence while $36.5 \%$ had some influence.

When examining whether provider level of importance differed based on provider characteristics and industry practices, significant differences were found with regard to how much influence a patient or caregiver was perceived to have over which factor therapy is prescribed $(p=.047)$ and which patients requested a switch in factor products most often $(p=.050)$. Specifically, in practices where patients or caregivers were perceived to have a strong influence over which factor therapy is prescribed, providers were more likely to rate less frequent dosing options as important or very important. Additionally, as patient or caregiver influence increased, providers rated patient/ caregiver requests as more important. Differences approaching significance were noted in how much 
Table 3. Perceptions of patient motivation leading to a request to change prescribed factor concentrate

\begin{tabular}{|c|c|c|c|c|c|}
\hline REASON & $\begin{array}{l}\text { NOT } \\
\text { IMPORTANT } \\
\text { N (\%) }\end{array}$ & $\begin{array}{l}\text { SOMEWHAT } \\
\text { IMPORTANT } \\
\text { N (\%) }\end{array}$ & $\begin{array}{l}\text { NEUTRAL } \\
\text { N (\%) }\end{array}$ & $\begin{array}{l}\text { IMPORTANT } \\
\text { N (\%) }\end{array}$ & $\begin{array}{l}\text { VERY } \\
\text { IMPORTANT } \\
\text { N (\%) }\end{array}$ \\
\hline Less frequent dosing option & $0(0)$ & $2(2.4)$ & $0(0)$ & $32(38.1)$ & $50(59.5)$ \\
\hline Lower out-of-pocked cost & $5(5.9)$ & $8(9.4)$ & $11(12.9)$ & $21(24.7)$ & $40(47.1)$ \\
\hline Insurance preferred drug list & $13(15.5)$ & $14(16.7)$ & $18(21.4)$ & $19(22.6)$ & $20(23.8)$ \\
\hline $\begin{array}{l}\text { Concerns about inhibitor } \\
\text { development }\end{array}$ & $2(2.4)$ & $15(17.6)$ & $12(14.1)$ & $30(35.3)$ & $26(30.6)$ \\
\hline $\begin{array}{l}\text { Strong commitment of manufacturer } \\
\text { to haemophilia community }\end{array}$ & $11(12.9)$ & $17(20.0)$ & $24(28.2)$ & $26(30.6)$ & $7(8.2)$ \\
\hline Patient/caregiver brand loyalty & $4(4.7)$ & $7(8.2)$ & $11(12.9)$ & $41(48.2)$ & $22(25.9)$ \\
\hline $\begin{array}{l}\text { Therapy recommended by friend/ } \\
\text { family }\end{array}$ & $4(4.8)$ & $10(11.9)$ & $13(15.5)$ & $45(53.6)$ & $12(14.3)$ \\
\hline $\begin{array}{l}\text { Therapy recommended by } \\
\text { pharmaceutical representative }\end{array}$ & 9 (10.6) & $19(22.4)$ & $21(24.7)$ & $28(32.9)$ & $8(9.4)$ \\
\hline $\begin{array}{l}\text { Poor response to current therapy } \\
\text { (breakthrough bleeds) }\end{array}$ & $0(0)$ & $3(3.5)$ & 9 (10.6) & $27(31.8)$ & $46(54.1)$ \\
\hline $\begin{array}{l}\text { Factor characteristics (volume to be } \\
\text { infused, mixing device, vial sizes) }\end{array}$ & $1(1.2)$ & $3(3.5)$ & $7(8.2)$ & $46(54.1)$ & 28 (32.9) \\
\hline $\begin{array}{l}\text { Patient/family's relationship with a } \\
\text { pharmaceutical representative }\end{array}$ & $11(12.9)$ & $12(14.1)$ & $14(16.5)$ & $29(34.1)$ & $19(22.4)$ \\
\hline $\begin{array}{l}\text { Recommendation by specialty } \\
\text { pharmacy }\end{array}$ & $17(20.0)$ & $13(15.3)$ & $16(18.8)$ & $30(35.5)$ & 9 (10.6) \\
\hline $\begin{array}{l}\text { Attendance to an industry sponsored } \\
\text { dinner }\end{array}$ & $17(20.0)$ & 9 (10.6) & $24(28.2)$ & 23 (27.1) & 12 (14.1) \\
\hline Other & $1(25.0)$ & $0(0.0)$ & $1(25.0)$ & $1(25.0)$ & $1(25.0)$ \\
\hline
\end{tabular}

influence providers have over which factor therapy is prescribed ( $p=.064)$, where providers with stronger influences were more likely to cite inadequate PK studies as an important or very important driving force for changing a patient's factor therapy regimen.

When reviewing whether the perceived patient level of importance differed based on provider characteristics and industry practices, significant differences were found in how much perceived influence a patient or caregiver has over which factor therapy is prescribed ( $p=.013$ ). Specifically, providers who perceived that patients had a strong influence over which factor therapy is prescribed were more likely to rate less frequent dosing options as being very important.

With regard to which population of patients switched factor products most, the adolescent age range (12-18 years old) was the most common (34.1\%), followed by $25-45$ year olds (30.5\%), 18-25 year olds (19.5\%), and patients $<12$ years (15.9\%). As the age of the patient decreased, less frequent dosing options were more likely to be rated as a very important driving force for switching factor therapy: $61.5 \%$ ranked less frequent dosing options as very important for those aged $<12$ years, $46.4 \%$ for $12-18$ years old, $20.0 \%$ for $18-25$ years old, and $36.0 \%$ for $25-45$ years old.

The majority of HTCs did not have standard protocols in place for previously untreated patients (PUPs), prophylaxis treatment, and immune tolerance induction (ITI): $43 \%$ had protocols for PUPs, 31\% had protocols for choice of factor concentrate for prophylaxis treatment, and $45.9 \%$ had protocols for ITI therapy.

With regard to the scope of practice for nonphysician prescribers (NP/PA), of those who responded, only $21.7 \%$ were able to initiate and/ or change prescriptions independently. Forty-seven percent (47.0\%) were able to submit prescriptions; however, any changes had to be discussed with the haematologist before submission. Thirty-one per cent (31.3\%) mentioned the haematologist being the primary prescriber. Haematologists, NPs, PAs, nurse coordinators and staff nurses had different patterns of responses to this question ( $p=.001)$. Of the haematologists who responded, $32.4 \%$ reported the haematologist being the primary prescriber, $18.9 \%$ allowed NPs and PAs to prescribe independently, and $48.6 \%$ required changes to be discussed prior to submission. Of the NP/PA 
respondents, $52.9 \%$ reported being able to prescribe independently, and $47.1 \%$ needed to discuss changes prior to submission. The majority of nurse coordinators (48.1\%) and staff nurses (50.0\%) reported haematologists being the primary prescriber.

\section{Attitudes toward industry}

Eighty-six percent (86.2\%) of respondents indicated that their institution allows pharmaceutical representatives to visit the office for in-person meetings. The frequency of these visits is most commonly yearly $(49.3 \%)$ or every six months (29.6\%). About half $(52.4 \%)$ of the HTCs sampled allow industry to interact with patients. Most respondents (77.4\%) do not participate in any manufacturer's speakers' bureaus. When asked about the primary source of information regarding new or existing therapies, respondents indicated the most common primary source of information being in-person symposium/presentations at medical conferences (39.3\%), medical journals (16.7\%), meeting with pharmaceutical sales representatives (11.9\%), meeting with pharmaceutical medical science liaisons (10.7\%), and their own research (9.5\%). When further evaluating the percentage of $\mathrm{HCPs}$ receiving information at medical conferences, $79.1 \%$ of haematologists, $94.4 \%$ of NPs, $100 \%$ of PAs, and $83.3 \%$ of nurse coordinators reported this as being their primary source.

\section{DISCUSSION}

The standard of care for managing patients with bleeding disorders is the replacement of missing clotting proteins with anti-haemophilic factor ${ }^{[3]}$. Currently, the haemophilia treatment landscape is becoming increasingly complex, with a change in focus from factor replacement to novel therapies, which continues to strongly influence the haemophilia population ${ }^{[4]}$.

This study found the most common driving forces in HCPs' prescribing practice in the US were poor responses to current therapy, non-adherence, inadequate $\mathrm{PK}$, and less frequent dosing options. These results were not surprising considering the multitude of factor therapy options available and the goal of optimising the level of protection patients have against having bleeding episodes. Patient and caregiver requests to switch treatment product was also a common driving force, although not one of the top five reasons identified. Differences in practice mean that patients have varying degrees of influence over which factor therapy is prescribed. In HTCs where patients were perceived to have a strong influence, patient/ caregiver requests were found to be a more important driving force. The perceived driving forces for patients to request a change in therapy differed slightly, with less frequent dosing options being the most common motivating factor leading to a switch, followed by poor response to current therapy, factor characteristics, out-of-pocket expenses, and brand loyalty. As a patient's age decreased, less frequent dosing was a more significant motivating factor to initiate a switch in therapy. It is commonly seen in practice that adolescents and young adults gravitate toward more convenient treatments, so this observation does not come as a surprise. The CHESS study, for example, found that having fewer weekly infusions was beneficial for the young adults versus prophylaxis, which can cause a burden on their daily quality of life ${ }^{[8.9]}$. Within the University of Miami (UM) HTC paediatric population, caregivers of young children tend to prefer less frequent dosing options but many are hesitant in trying currently available novel therapies.

This study also confirmed that the majority of HTCs do not have protocols implemented for PUPs, ITI, and prophylaxis treatment. A lack of standardisation in haemophilia care teaching is found in the literature ${ }^{[10]}$, and this study found a similar trend with a deficiency of protocols for these topics. The haemophilia treatment landscape is evolving, and this brings an opportunity for future research to determine best practices in these areas, with consideration of implementing a more standardised plan of care for bleeding disorder patients.

$\mathrm{HCPs}$ responding to the survey identified attendance at medical conferences as their primary source of information, followed by medical journals, and interactions with pharmaceutical sales representatives. However, other resources are available for HCPs to expand their knowledge and gather additional information on treatment options for bleeding disorder patients. The National Hemophilia Foundation (NHF) and the WFH for example, are organisations committed to uniting providers of the bleeding disorder community. Both organisations host annual conferences that provide HCPs with updated treatment options as well as therapies in the pipeline, which ultimately enable a provider to exercise their best clinical judgement in advising and treating their patients ${ }^{[1]}$. Alongside training available online covering topics such as treatment options, joint health, case studies and special issues in haemophilia, the Partners in Bleeding Disorders Education Program provides standardised, comprehensive education on bleeding and clotting disorders to HTC providers, including, but not limited to, nurses, social workers and physical 
therapists ${ }^{[6]}$. HCPs can register to attend a basic or advanced course free of charge through educational grants from Shire and Genentech.

The majority of HCPs responded that their institutions allow in-person meetings with pharmaceutical representatives, which can include, but are not limited to, sales representatives or medical science liaisons (MSL). All HTCs function differently and have different practices in place with regards to interactions with pharmaceutical representatives and how visits are monitored. Within the UM HTC, HCPs meet with pharmaceutical representatives at their discretion, whether it be quarterly or biannually. Meetings are scheduled with sales representatives or MSLs to receive updated information on products, explore new data on a particular therapy, review services available for patients, and other support to assist with insurance coverage. At the UM HTC, these meetings do not impact prescribing practices, and can be helpful in terms of providing HCPs with information that helps with selecting treatment options. Contact with pharmaceutical companies can also be useful in terms of access to grants, which have been used at the UM HTC to provide patient education.

With the addition of more factor replacement products, novel therapies, and the promise of gene therapy, decision-making becomes more complex and implies a growing need to take into account patient preferences and goals. The majority of HCPs reported patients and caregivers have a strong influence over what therapies are prescribed. Shared decision-making is essential in patient-centred care, and HCPs should continue to focus on creating individualised treatment plans that take into account patient goals and preferences, along with disease-specific aspects of care ${ }^{[11-13]}$.

The scope of practice for NPs and PAs includes the ability to initiate and manage treatment, including the prescription of medications. Currently 23 US states allow NPs to practice autonomously, while the remaining states require physician oversight ${ }^{[14]}$. There was consistency across all types of providers where around half allow NPs and PAs to make changes to factor therapy with consult. However, this study found that less than a quarter of NPs/PAs are able to initiate and/or change prescriptions independently without prior discussion with a haematologist. Interestingly, the NPs and PAs were most likely to respond to being able to make changes without consultation compared to the other positions. Consideration should be taken within HTCs to empower NPs/PAs to function within their full scope of practice.
A 340B Drug Pricing Program is a federal program that allows certain hospitals and health care providers to receive prescription medications at significantly reduced prices from drug manufacturers ${ }^{[7]}$. This enables HTCs to purchase haemophilia treatments at discounted prices for patients and insurers. The savings help support HTCs in providing services and programs that directly benefit all HTC patients ${ }^{[15-17]}$. Each HTC 340B program is an individual program; therefore, it is difficult to generalise whether having a program might influence prescribing practices. However, having a 340B program at the UM HTC does not impact prescribing practices, and the best and most appropriate product is prescribed for the patients.

\section{Limitations}

This study was a self-directed survey with self-reported response biases. The study response rate of $15.9 \%$ resulted in a small sample size with the limitations of self-selection ${ }^{[18]}$. The number of valid responses also varied significantly by geographic region resulting in an uneven distribution that did not allow for regional comparisons.

The response rate was also impacted after discovering the CDC HTC directory is not routinely updated and many e-mail addresses belonged to HCPs who no longer worked at a particular HTC or were invalid. The CDC and regional coordinators need to maintain a reliable directory to better understand the staff delivering care at HTCs, and more importantly, provide patients with a dependable resource for contacting HTC providers, which is common when patients are moving home or traveling. Due to the lower response rate, we were unable to draw statistically significant conclusions.

Despite the low response rate, this is the first study to examine prescribing practices among HTC providers in the US and provides interesting insight.

\section{CONCLUSION}

For decades, the standard of care for haemophilia has been the use of factor replacement to prevent or treat bleeding episodes. There are many current and emerging therapies for haemophilia, with a change in focus from factor replacement to thrombin generation. The range of treatment options available offers increased choices, and patient-centric prophylaxis should be a key focus for haemophilia care. Against this landscape, shared decision-making should be a consideration for HTCs, as it has been shown to improve treatment adherence, patient satisfaction, and overall health ${ }^{[11]}$. 
This study supports further research on current and emerging treatment options, along with further research for PUPs, and ITI, in order to help establish associated best practices in haemophilia care. A future study could be considered to capture a larger response rate for this topic. Additional research with a focus on evaluating the patients' perspective on current treatment options and driving forces for switching therapies could help identify potential areas of unmet need.

\section{ACKNOWLEDGEMENTS}

All authors equally contributed to the research design, research analysis and authorship of manuscript. We would like to thank the HTC HCPs who participated in this study.

The authors have advised no interests that might be perceived as posing conflict or bias.

This study reports on a survey to which participants responded knowing that any comments may be reported.

\section{ORCID}

Maya Bloomberg (iD https://orcid.org/0000-0002-9973-9539 Krysten Sargenton (iD https://orcid.org/0000-0002-8016-582X Karina Gattamorta (iD) https://orcid.org/0000-0001-5827-1389 Debbie Anglade (iD https://orcid.org/0000-0003-4642-6624

\section{REFERENCES}

1. Valentino LA, Oza VM. Blood safety and the choice of antihemophilic factor concentrate. Pediatr Blood Cancer 2006; 47: 245-54. doi: 10.1002/pbc.20895.

2. Zimmerman B, Valentino A. Haemophilia: in review. Pediatr Rev 2013; 34: 289-95. doi: 10.1542/pir.34-7-289.

3. Srivastava A, Brewer AK, Mauser-Bunschoten EP, et al. Guidelines for the management of haemophilia. Haemophilia 2013; 19: e1-e47. doi: 10.1111/j.1365-2516.2012.02909.x.

4. Berntorp E, Shapiro AD. Modern haemophilia care. Lancet 2012; 379: 1447-56. doi: 10.1016/S0140-6736(11)61139-2.

5. Center for Disease Control and Prevention. Haemophilia treatment centers. Available from https://www.cdc.gov/ ncbddd/haemophilia/htc.html (accessed 1 May 2019).

6. Partners in Bleeding Disorder Education. Available from www.partnersprn.org (accessed 1 May 2019).

7. Health Resources \& Services Administration. 340B Drug Pricing Program. Available from https://www.hrsa.gov/opa/ index.html (accessed 9 September 2020).

8. O'Hara J, Hughes D, Camp C, Burke T, Carroll L, Diego DG. The cost of severe haemophilia in Europe: the CHESS study.
Orphanet J Rare Dis 2017; 12(1): 106. doi: 10.1186/s13023017-0660-y. PMID: 28569181; PMCID: PMC5452407.

9. Pedra G, Christoffersen P, Khair K, et al. The impact of factor infusion frequency on health-related quality of life in people with haemophilia. J Haem Pract 2020; 7(1): 102-109. doi: 10.17225/jhp00158.

10. Santaella M, Bloomberg M, Anglade D. Home infusion teaching practices at federally funded haemophilia treatment centers in the United States of America. Res Pract Thromb Haemost 2017; 1(1): 81-89. doi:10.1002/rth2.12020.

11. Nossair F, Thornburg CD. The role of patient and healthcare professionals in the area of new haemophilia treatments in developed and developing countries. Ther Adv Hematol 2018; 9: 239-49. doi: 10.1177/2040620718784830.

12. Barry MJ, Edgman-Levitan S. Shared decision making - the pinnacle of patient-centered care. N Engl J Med 2012; 366: 780-1. doi: 10.1056/NEJMp1109283.

13. Elwyn G, Laitner S, Coulter A, Walker E, Watson P, Thomson R. Implementing shared decision making in the NHS. BMJ 2010; 341: c5146. doi: 10.1136/bmj.c5146.

14. Nurse Journal. What is a family nurse practitioner (FNP)? Available from https://nursejournal.org/family-practice/rolescope-of-practice-of-a-family-nurse-practitioner/ (accessed 27 November 2019).

15. American Hospital Association. Fact Sheet: The 340B Drug Pricing Program. 2019. Available from https://www.aha.org/ system/files/2019-01/fact-sheet-340b-0119.pdf (accessed 7 August 7 2020).

16. Medicare Payment Advisory Commission. Overview of the 340B Drug Pricing Program. 2015. Available from http:// www.medpac.gov/docs/default-source/reports/may-2015report-to-the-congress-overview-of-the-340b-drug-pricingprogram.pdf?sfvrsn $=0$ (accessed 7 August 7 2020).

17. National Haemophilia Foundation (NHF). NHF Policy Statement Haemophilia Treatment Center Participation in the 340B Drug Discount Program. NHF, 2015. Available from https://www.haemophilia.org/sites/default/files/document/ files/NHF-Position-Statement-Regarding-HaemophiliaTreatment-Center-Participation-in-the-340B-Drug-DiscountProgram.pdf (accessed 7 August 7 2020).

18. Polit DF, Beck CT. Nursing Research: Generating and Assessing Evidence for Nursing Practice. 9th edition. Philadelphia, PA: Lippincott, Williams and Wilkins; 2012.

HOW TO CITE THIS ARTICLE:

Bloomberg M, Sargenton K, Gattamorta K, Anglade D. Knowledge, attitude and practice of health care providers toward prescribing factor replacement federally funded haemophilia treatment centres in the United States. J Haem Pract 2020; 7(1): 121-128. https://doi.org/10.17225/ jhp00165.

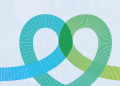

The Journal of Haemophilia Practice
An open-access journal for sharing experience in the care of people with bleeding disorders

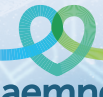

haemnet 